\title{
Manifestações Patológicas em Pavimentos Asfálticos nos Centros Urbanos
}

\author{
A. R. S. Oliveira ${ }^{1 *}$, M. A. Salomão ${ }^{1}$, R. C. $\operatorname{Santos}^{1}$, M. T. G. Barbosa ${ }^{1}$ \\ *Autor de Contato: amanda.rodrigues@engenharia.ufjf.br \\ ${ }^{1}$ Programa de Pós Graduação em Ambiente Construído, Faculdade de Engenharia. Universidade Federal de Juiz de \\ Fora, Juiz de Fora, Brasil
}

\begin{abstract}
RESUMO
As vias urbanas são fundamentais para o desenvolvimento social e econômico das cidades, auxiliando os meios de transportes e a mobilidade urbana. O objetivo do trabalho é efetuar o levantamento das anomalias em pavimentos asfálticos das principais vias de acesso localizadas na cidade de Juiz de Fora (MG) que tendem a comprometer a mobilidade urbana na cidade. Sendo assim, é efetuada uma revisão bibliográfica, bem como um estudo de caso, através de vistoria visual nas principais vias localizadas nas 8 (oito) regiões do município bem como, apresenta-se as técnicas de recuperação dos pavimentos. Finalmente, acrescenta-se a relevância do planejamento dos serviços da restauração e manutenção para a garantia da vida útil dos pavimentos e para a qualidade e segurança trânsito de veículos e pedestres.
\end{abstract}

Palavras-chave: mobilidade urbana; pavimentação; via pública; manifestações patológicas.

\begin{abstract}
Urban roads are fundamental for the social and economic development of cities, supporting means of transport and urban mobility. The objective of the work is to survey the anomalies in asphalt
\end{abstract}


pavements of the main access roads located in the city of Juiz de Fora (MG) that tend to compromise urban mobility in the city. Thus, a bibliographical review is carried out, as well as a case study, through a visual inspection of the main roads located in the 8 (eight) regions of the city, as well as the pavement recovery techniques. Finally, it adds the relevance of planning restoration and maintenance services to guarantee the useful life of the pavements and for the quality and safety of traffic for vehicles and pedestrians.

Keywords: urban mobility; paving; public highway; pathological manifestations.

\section{RESUMEN}

Las vías urbanas son fundamentales para el desarrollo social y económico de las ciudades, ayudando a los medios de transporte y la movilidad urbana. El objetivo del trabajo es relevar las anomalías en pavimentos asfálticos de las principales vías de acceso ubicadas en la ciudad de Juiz de Fora (MG) que tienden a comprometer la movilidad urbana en la ciudad. Para ello, se realiza una revisión bibliográfica, así como un estudio de caso, a través de una inspección visual de las principales vías ubicadas en las 8 (ocho) regiones de la ciudad, así como las técnicas de recuperación del pavimento. Finalmente, se suma la relevancia de planificar los servicios de restauración y mantenimiento para garantizar la vida útil de las aceras y para la calidad y seguridad del tráfico de vehículos y peatones.

Palabras clave: mobilidad urbana; pavimentación; vía pública; manifestaciones patológicas.

\section{INTRODUÇÃO}

Nas cidades, os deslocamentos ocorrem através do sistema viário, que pode ser definido como o conjunto de vias de circulação públicas que têm por objetivo fornecer mobilidade, ou seja, promover a circulação de pedestres e dos meios de transportes, bem como servir de estacionamento para os veículos (MELO, 2004). As vias de circulação urbanas são geralmente revestidas com pavimentação asfáltica que proporcionam conforto na rodagem, capacidade de suporte às cargas, segurança e conforto visual aos usuários.

Entre os anos 2000 e 2018 ocorreu um incremento superior a 300\% na frota de veículos motorizados nas cidades brasileiras, o que resulta numa proporção de 1 automóvel para cada 4,4 habitantes (DENATRAN, 2019). No entanto, a malha viária brasileira, pequena e urbanizada nas cidades, não obteve investimentos suficientes para se adequar a essa nova realidade e, as deficiências no transporte público, resultaram em graves consequências para a mobilidade urbana, como, por exemplo, congestionamentos constantes e elevação do número de acidentes de trânsito. Deve-se considerar, inclusive, que os pavimentos urbanos possuem a função de transmitir conforto e segurança aos usuários e uma infraestrutura adequada para sua utilização. Entretanto, o alto volume de tráfego, o dimensionamento inadequado, a ausência de manutenção e reparos pelos órgãos responsáveis, entre outros, resultam em elevado número de manifestações patológicas (ALMEIDA, 2019), sendo a administração pública, responsável por gerir as vias urbanas, através de obras e serviços de manutenção e conservação (DANIELESKI, 2004).

A escassez de recursos investidos na manutenção dos pavimentos reflete-se na qualidade da mobilidade urbana, principalmente quando se verificam anomalias como: deformações, desgaste, buracos, falta de sinalização, incluindo a pintura do pavimento. De acordo com o Departamento Nacional de Infraestrutura e Trânsito (DNIT (2006)), qualquer mudança na característica do 
pavimento, por motivos de falhas executivas ou de utilização, é considerada como um defeito ou anomalia que poderá afetar a condição de rolamento, alterando a trafegabilidade e o conforto do usuário, e/ou a capacidade de carga, comprometendo a estrutura do pavimento. Esses defeitos estão relacionados ao tipo de materiais utilizados e ao comportamento mecânico de cada estrutura (MARQUES, 2014 apud MENDES, 2019).

Segundo Fernandes (1996, apud DANIELESKI, 2004) a pavimentação urbana possui características que a difere da pavimentação rodoviária, como por exemplo, as redes de infraestrutura sob os pavimentos, a elevada incidência de tráfego de veículos leves, baixa velocidade dos veículos, fluxo descontínuo, dentre outros. Essas características podem acelerar o processo de deterioração dos pavimentos, já que são responsáveis por fadiga na estrutura do pavimento decorrente das deformações e do grau de fissuração (SILVA; CARNEIRO, 2014 apud MENDES, 2019).

Deve-se considerar, inclusive, que os processos de desgaste das vias nos centros urbanos são potencializados pela ação climática já que a elevada densidade de áreas construídas e pavimentadas resulta no aumento da temperatura do ar e das superfícies do meio urbano, fenômeno conhecido como "ilha de calor" (GARTLAND, 2010 apud CALLEJAS, DURANTE \& ROSSETI, 2015).

Algumas das manifestações patológicas mais comuns que podem surgir nas ruas de centros urbanos são as trincas e os buracos que podem ocasionar além de acidentes de trânsito, transtornos para os motoristas, como por exemplo, falhas mecânicas nos automóveis, atrasos nos deslocamentos, entre outros. Portanto, a gestão das vias e o bom estado de conservação, causam impactos positivos na percepção e experiência do usuário, como conforto, segurança, satisfação e redução dos riscos de acidentes e perdas materiais (ALMEIDA, 2019).

Diante do exposto, o objetivo do trabalho é identificar os aspectos que impactam na vida útil dos pavimentos asfálticos no contexto urbano e elucidar as anomalias da pavimentação. Para tanto, efetuou-se o estudo em trechos de pavimentos localizados na cidade de Juiz de Fora- MG, através do levantamento das manifestações patológicas a fim de verificar a ocorrência e a incidências das mesmas nas vias da cidade, a fim de se propor medidas corretivas e de manutenção para os defeitos localizados. Dessa forma, o estudo visa compreender o comportamento de pavimentos asfálticos e suas patologias, bem como reconhecer na prática os processos de degradação, a fím de se propor diretrizes para o aumento da durabilidade e vida útil dos pavimentos urbanos.

\section{O SISTEMA VIÁRIO URBANO}

Os deslocamentos urbanos ocorrem através do sistema viário, que é o conjunto de vias de circulação públicas que propiciam a mobilidade urbana de pedestres e meios de transporte. Neste contexto, as vias urbanas são definidas, de acordo com o Código de Trânsito Brasileiro (CTB), como "ruas, avenidas, vielas, caminhos e similares, abertos à circulação pública, situados na área urbana, caracterizados principalmente por possuírem imóveis edificados ao longo de sua extensão", podendo ser subdivididas em: via de trânsito rápido, via local, via arterial e via coletora.

A classificação das vias, conforme Carvalho (2002, apud CAETANO, 2013) objetiva a melhoria da vivência social e da sua capacidade, tendo como principais funções a circulação de veículos e pedestres; estacionamento de veículos; suporte para as infraestruturas urbanas como redes de água, esgoto, eletricidade, gás, etc.; instalação de mobiliário urbano; iluminação nas edificações; dentre outros.

Savietto (2017) destaca como desvantagens do sistema viário urbano o elevado custo (superior a $50 \%$ do custo total da urbanização); o elevado índice de ocupação (entre 20 a 25\% do solo urbano); o tipo de revestimento e estrutura empregado e a necessidade de sinalização horizontal.

A NBR 7207 (ABNT, 1982) define os pavimentos empregados nos centros urbanos como "uma estrutura construída após terraplenagem e destinada econômica e simultaneamente, em seu 
conjunto a: resistir e distribuir ao subleito os esforços verticais produzidos pelo tráfego; melhorar as condições de rolamento quanto à comodidade e segurança; resistir aos esforços horizontais que nela atuam, tornando mais durável a superfície de rolamento." Sendo assim, são divididos em duas categorias, a saber: pavimentos rígidos (concreto de cimento Portland constituídos basicamente por três camadas de revestimento, base e subleito que possuem alta rigidez e resistência para amortecerem as cargas recebidas) e pavimentos flexíveis ou asfálticos (cujos revestimentos são compostos por uma mistura de agregados e ligantes asfálticos, constituídos por diversas camadas de revestimento, base, sub-base e subleito) (HORONJEFF, 1966 apud QUIRINO, 2013).

As vias urbanas são, em sua maioria, constituídas por pavimentos flexíveis, onde o revestimento asfáltico é a camada responsável por resistir aos esforços de tráfego, impermeabilizar o pavimento e melhorar as condições de rolamento. As tensões e deformações causadas pelas cargas do tráfego estão associadas ao surgimento de anomalias como o trincamento e a fadiga dessa camada, que também podem ser causados pelo envelhecimento do ligante asfáltico, ação climática, entre outros. (BERNUCCI et. al., 2006). Dessa forma, as manifestações patológicas nas pistas dos pavimentos podem surgir ao longo do tempo da sua vida de serviço por motivos de execução e/ou utilização (vide Quadro 1, (DNIT, 2003)), reduzindo consequentemente sua durabilidade e sua vida útil (Fernandes Jr (1999, apud FRANÇA; TÁRSIS; MADAY, 2017)).

Como esses processos patológicos ocorrem ao longo do tempo, torna-se necessário que sejam realizadas operações de manutenção nas vias, para que se garanta a qualidade e a durabilidade do pavimento (FERNANDES JR; ODA; ZERBINI, 2011 apud SAVIETTO, 2017).

Quadro 1 - Definição das patologias asfálticas.

\begin{tabular}{|c|l|}
\hline Anomalia & \multicolumn{1}{|c|}{ Descrição } \\
\hline Fenda & Descontinuidade na superfície do pavimento que conduza a aberturas. \\
\hline Afundamento & $\begin{array}{l}\text { Deformação permanente caracterizada por depressão da superfície do } \\
\text { pavimento. }\end{array}$ \\
\hline $\begin{array}{c}\text { Ondulação ou } \\
\text { Corrugação }\end{array}$ & $\begin{array}{l}\text { Deformação caracterizada por ondulações ou corrugações transversais na } \\
\text { superfície do pavimento. }\end{array}$ \\
\hline Escorregamento & $\begin{array}{l}\text { Deslocamento do revestimento em relação à camada subjacente do pavimento, } \\
\text { com aparecimento de fendas em forma de meia-lua. }\end{array}$ \\
\hline Exsudação & Excesso de ligante betuminoso na superfície do pavimento. \\
\hline Desgaste & $\begin{array}{l}\text { Efeito do arrancamento progressivo do agregado do pavimento, caracterizado } \\
\text { por aspereza superficial do revestimento e provocado por esforços tangenciais } \\
\text { causados pelo tráfego. }\end{array}$ \\
\hline $\begin{array}{c}\text { Panela ou } \\
\text { Buraco }\end{array}$ & $\begin{array}{l}\text { Cavidade que se forma no revestimento por diversas causas podendo alcançar } \\
\text { as camadas inferiores, provocando a desagregação dessas camadas. }\end{array}$ \\
\hline Remendo & $\begin{array}{l}\text { Panela preenchida com uma ou mais camadas de pavimento na operação } \\
\text { denominada de “tapa-buraco”. }\end{array}$ \\
\hline
\end{tabular}

Como esses processos patológicos ocorrem ao longo do tempo, torna-se necessário que sejam realizadas operações de manutenção nas vias, para que se garanta a qualidade e a durabilidade do pavimento (FERNANDES JR; ODA; ZERBINI, 2011 apud SAVIETTO, 2017).

\section{MATERIAIS E MÉTODOS}


De acordo com Bernucci et. al. (2006), “a avaliação funcional de um pavimento relaciona-se à apreciação da superfície dos pavimentos e como este estado influencia no conforto ao rolamento". Sendo assim, os defeitos nos pavimentos asfálticos são os danos na superfície que podem ser observados a olho nu e classificados conforme as terminologias estabelecidas pela norma do DNIT $005 / 2003$.

Nesse contexto, o presente trabalho consistiu no levantamento dos defeitos, ou seja, no diagnóstico das vias públicas, bem como a apresentação de soluções ou conjunto de alternativas adequadas à restauração do pavimento. Dessa forma, a metodologia é dividida em duas etapas: a primeira referese a revisão bibliográfica e, a segunda no levantamento de dados em campo, em vias específicas localizadas na cidade de Juiz de Fora (MG).

Salienta-se que a cidade Juiz de Fora (vide Figura 1 (ACESSA, 2021; PJF, 2021)) localizada na região da Zona da Mata do estado de Minas Gerais, possui área de $1.435 .749 \mathrm{~km}^{2}$ e uma população de cerca 516 mil habitantes (IBGE, 2010). A cidade é dividida em oito regiões e cada uma dessas regiões é composta por diversos bairros. De acordo com o mapa, definiu-se as principais vias de acesso em cada uma das regiões que compõem a cidade, considerando sua importância e dinâmica para o trânsito do município, bem como o elevado fluxo de deslocamento e, consequentemente, o maior número de usuários, conforme ilustrado na Figura 2.

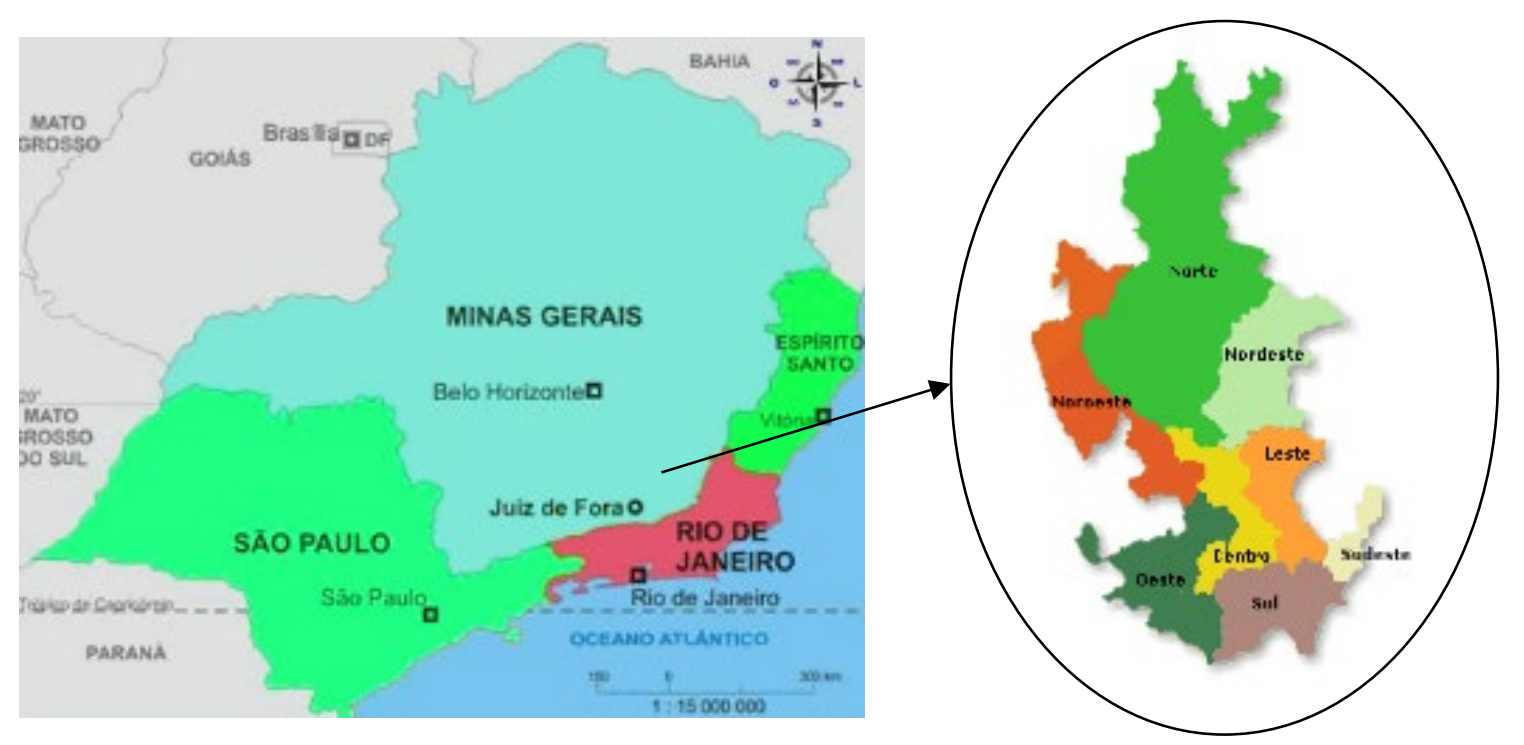

Figura 1. Localização e subdivisão da cidade de Juiz de Fora.

O procedimento de vistoria das vias públicas pavimentadas localizadas nas regiões de estudo (vide Figura 2) consistiu em uma análise visual e cadastro dos defeitos e irregularidades existentes, sendo adotado, inclusive o registro fotográfico das principais anomalias existentes nos pavimentos em cada região de estudo. A metodologia adotada permitiu identificar e mapear as falhas, a fim de propor soluções de reparação e recuperação das vias urbanas contidas na bibliografia, possibilitando a melhoria da mobilidade urbana no município. 


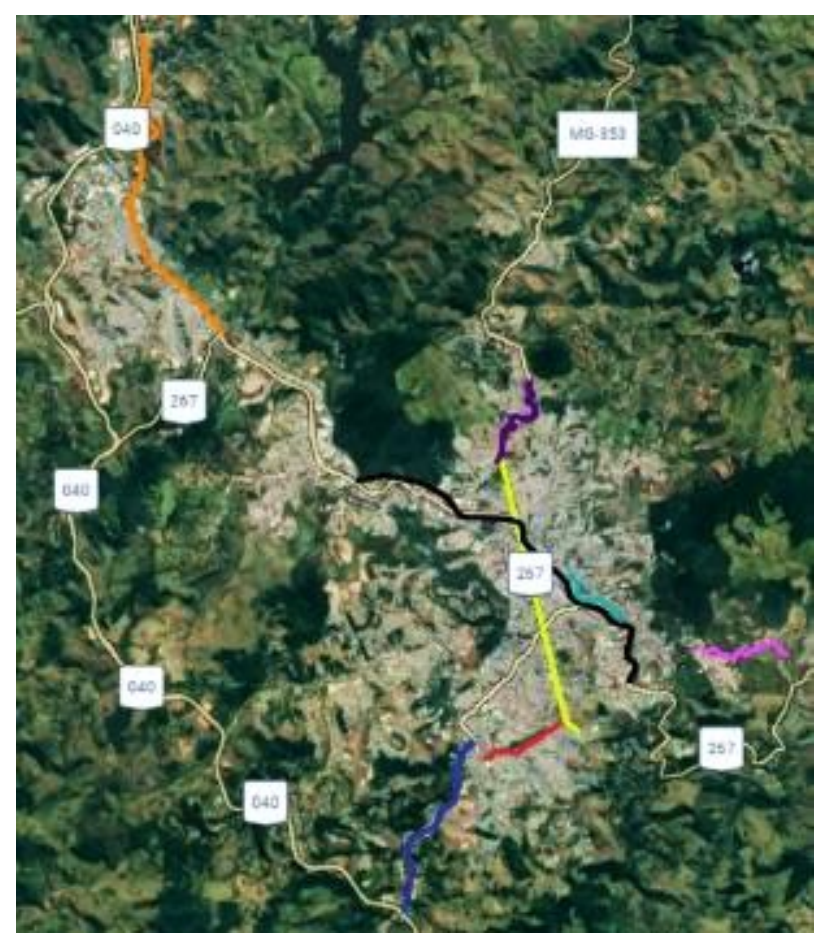

Legenda:

\begin{tabular}{|c|r|}
\hline Região & \multicolumn{1}{|c|}{ Logradouro } \\
\hline Norte & Av. Juscelino Kubitscheck \\
\hline Noroeste & Av. Brasil \\
\hline Central & Av. Barão do Rio Branco \\
\hline Oeste & Av. Deusdedith Salgado \\
\hline Leste & Av. Sete de Setembro \\
\hline Sul & Rua Ibitiguaia \\
\hline Nordeste & Rua Paracatu \\
\hline Sudeste & Alameda Ilva Melo Reis \\
\hline
\end{tabular}

Figura 2. Ilustração da área de estudo.

Dessa forma, as vias selecionadas (Figura 2) foram percorridas de modo a identificar as manifestações patológicas mais recorrentes e classificá-las de acordo com a norma do DNIT005/2003.

\section{RESULTADOS E DISCUSSÕES}

O Quadro 2 apresenta um resumo das manifestações patológicas identificadas em cada uma das principais vias de acesso das regiões do município. Salienta-se que devido à grande ocorrência das manifestações patológicas durante todo o percurso (estima-se que mais $60 \%$ do pavimento possui uma ou mais anomalia) não foi possível quantificar a área degradada e, portanto, realizou-se um levantamento qualitativo das falhas.

Analisando o Quadro 2 verifica-se a elevada incidência de manifestações patológicas nos pavimentos destacando-se a alta ocorrência de buracos, trincas e remendos, conforme se verifica nas Figuras 3 a 5.

A fim de melhor ilustrar a incidência das manifestações patológicas detectadas efetuou-se uma análise mais detalhada onde obteve-se o Gráfico 1 que apresenta a ocorrência das anomalias em todas as regiões. $\mathrm{O}$ objetivo de tal estudo consiste em identificar qual é a principal anomalia existente nas vias públicas e identificar a principal causa das mesmas, se está no processo (técnica de execução, incluindo especificação dos materiais) ou nos serviços de manutenção. 
Quadro 2 - Dados coletados no levantamento de campo.

\begin{tabular}{|c|c|c|c|c|c|c|c|c|}
\hline \multirow[b]{2}{*}{ } & \multicolumn{8}{|c|}{ Manifestação patológica } \\
\hline & $\stackrel{\overparen{E}}{:}$ & & 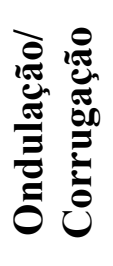 & 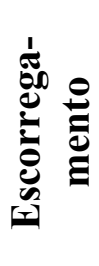 & 氕 & 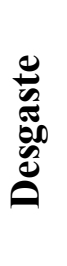 & 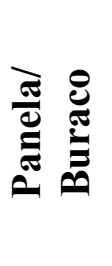 & 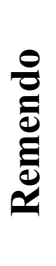 \\
\hline Centro & $\mathrm{X}$ & $\mathrm{X}$ & & $\mathrm{X}$ & & $X$ & $\mathrm{X}$ & $\mathrm{X}$ \\
\hline Leste & $\mathrm{X}$ & $\mathrm{X}$ & $\mathrm{X}$ & $\mathrm{X}$ & & $\mathrm{X}$ & $\mathrm{X}$ & $\mathrm{X}$ \\
\hline Nordeste & $\mathrm{X}$ & & & & & & $\mathrm{X}$ & $\mathrm{X}$ \\
\hline Noroeste & $\mathrm{X}$ & & & & & $X$ & $\mathrm{X}$ & $\mathrm{X}$ \\
\hline Norte & $\mathrm{X}$ & $\mathrm{X}$ & $\mathrm{X}$ & & & $\mathrm{X}$ & $\mathrm{X}$ & $\mathrm{X}$ \\
\hline Oeste & $\mathrm{X}$ & & & & & $\mathrm{X}$ & $\mathrm{X}$ & $\mathrm{X}$ \\
\hline Sudeste & $\mathrm{X}$ & & & & & $\mathrm{X}$ & $\mathrm{X}$ & $\mathrm{X}$ \\
\hline Sul & $\mathrm{X}$ & & & & & $\mathrm{X}$ & $\mathrm{X}$ & $\mathrm{X}$ \\
\hline
\end{tabular}

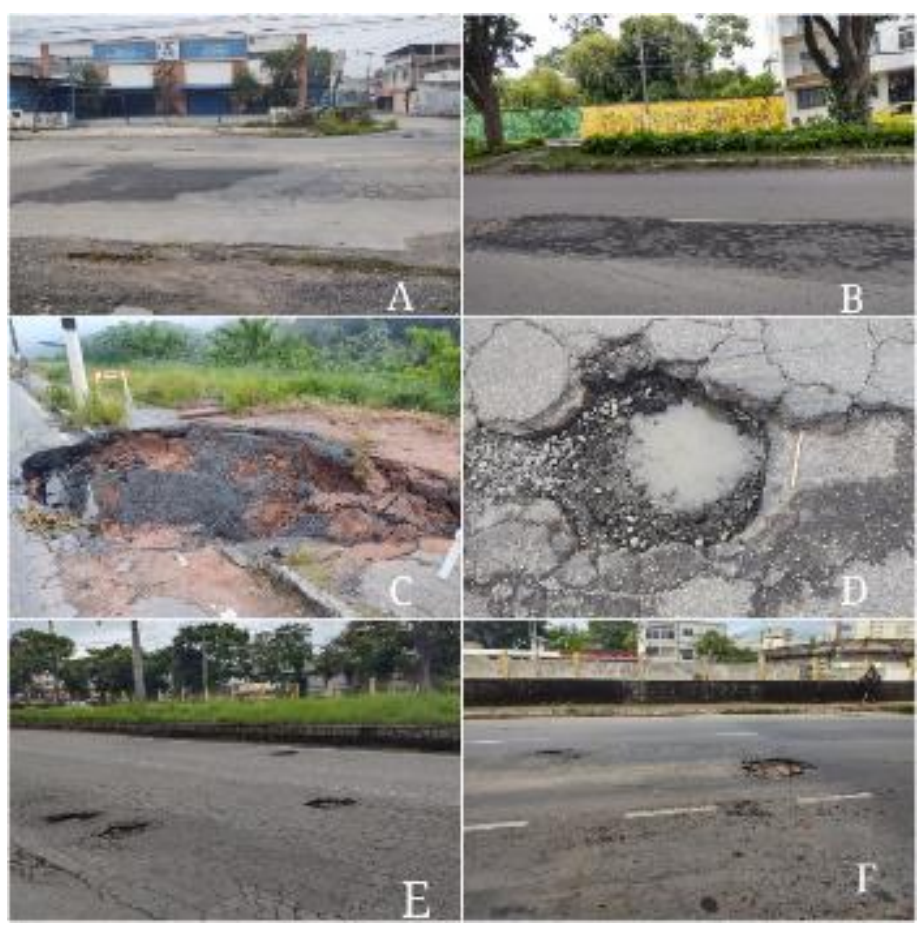

Legenda:

B

\begin{tabular}{|c|c|l|}
\hline Figura & Região & \multicolumn{1}{|c|}{ Anomalias } \\
\hline A & Noroeste & $\begin{array}{l}\text { Remendo, } \\
\text { afundamento, } \\
\text { desgaste, trincas }\end{array}$ \\
\hline B & Centro & $\begin{array}{l}\text { Remendo, trincas } \\
\text { interligadas }\end{array}$ \\
\hline C & Noroeste & Panela \\
\hline D & Sul & Buraco, trincas \\
\hline E & Norte & $\begin{array}{l}\text { Trincas } \\
\text { interligadas, } \\
\text { buracos }\end{array}$ \\
\hline F & Noroeste & Buracos, desgaste \\
\hline
\end{tabular}

Figura 3. Manifestações patológicas nas vias públicas em estudo. 


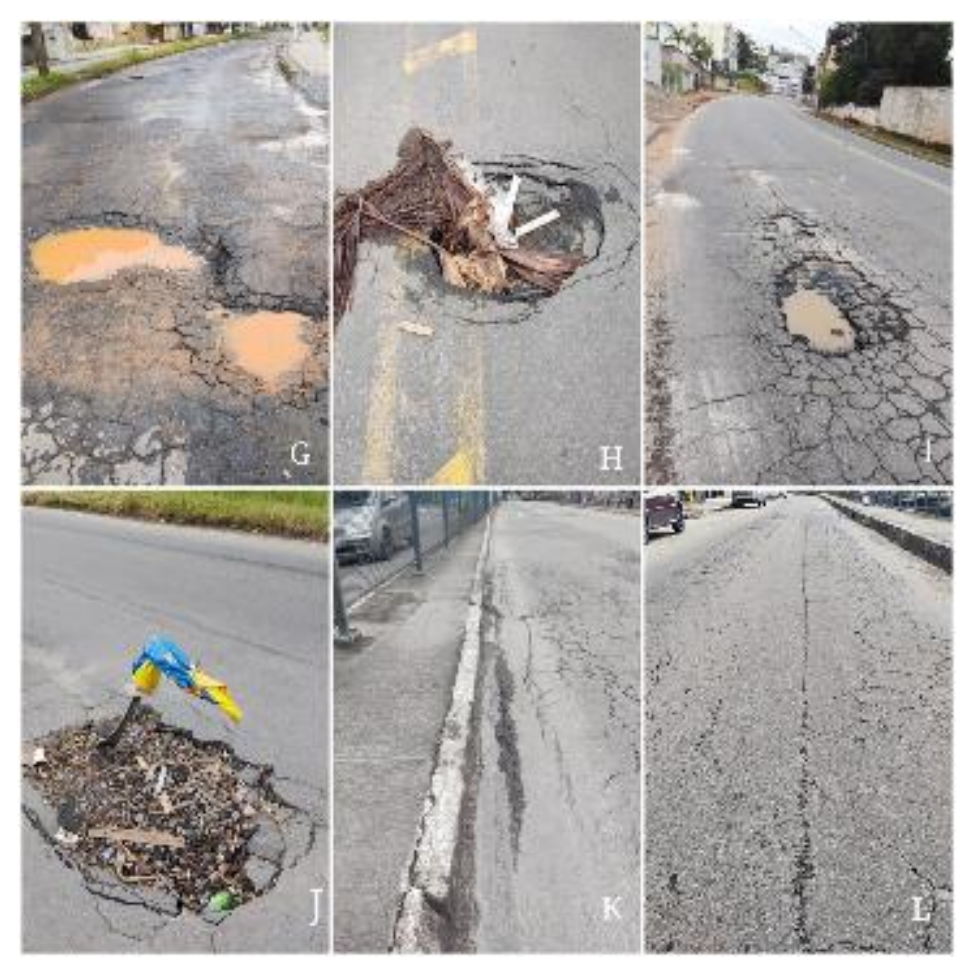

Legenda:

\begin{tabular}{|c|c|l|}
\hline Figura & Região & \multicolumn{1}{|c|}{ Anomalias } \\
\hline G & Centro & $\begin{array}{l}\text { Buracos, trincas } \\
\text { interligadas }\end{array}$ \\
\hline H & Centro & Panela \\
\hline I & Nordeste & $\begin{array}{l}\text { Buracos, trincas } \\
\text { interligadas }\end{array}$ \\
\hline J & Nordeste & Panela \\
\hline K & Centro & Escorregamento \\
\hline L & Sul & Trinca longitudinal \\
\hline
\end{tabular}

Figura 4. Manifestações patológicas nas vias públicas em estudo.

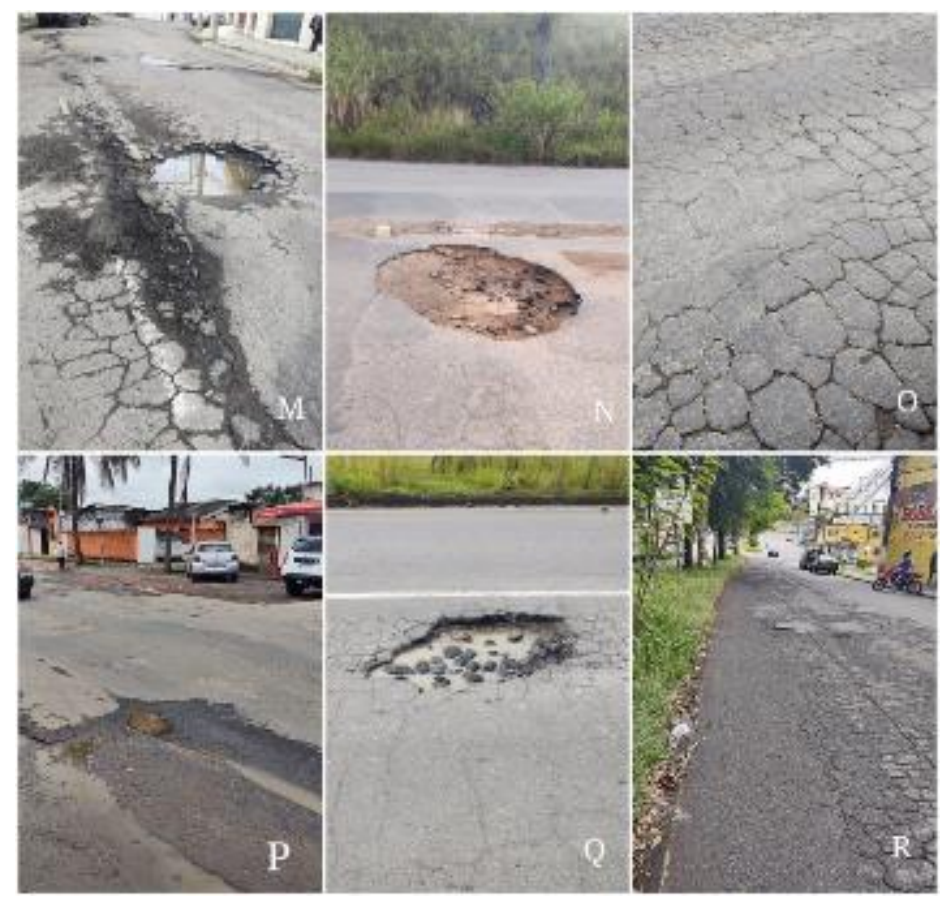

Legenda:

\begin{tabular}{|c|c|l|}
\hline Figura & Região & \multicolumn{1}{|c|}{ Anomalias } \\
\hline $\mathrm{M}$ & Leste & $\begin{array}{l}\text { Buraco, } \\
\text { afundamento, } \\
\text { ondulação, trincas }\end{array}$ \\
\hline $\mathrm{N}$ & Sudeste & $\begin{array}{l}\text { Panela, remendo, } \\
\text { desgaste }\end{array}$ \\
\hline $\mathrm{O}$ & Norte & $\begin{array}{l}\text { Trincas } \\
\text { interligadas }\end{array}$ \\
\hline $\mathrm{P}$ & Nordeste & Panela \\
\hline $\mathrm{Q}$ & Oeste & Buraco, trincas \\
\hline $\mathrm{R}$ & Oeste & $\begin{array}{l}\text { Corrugação, } \\
\text { trincas, remendos }\end{array}$ \\
\hline
\end{tabular}

Figura 5. Manifestações patológicas nas vias públicas em estudo. 
Gráfico 1 - Patologias mais recorrentes:

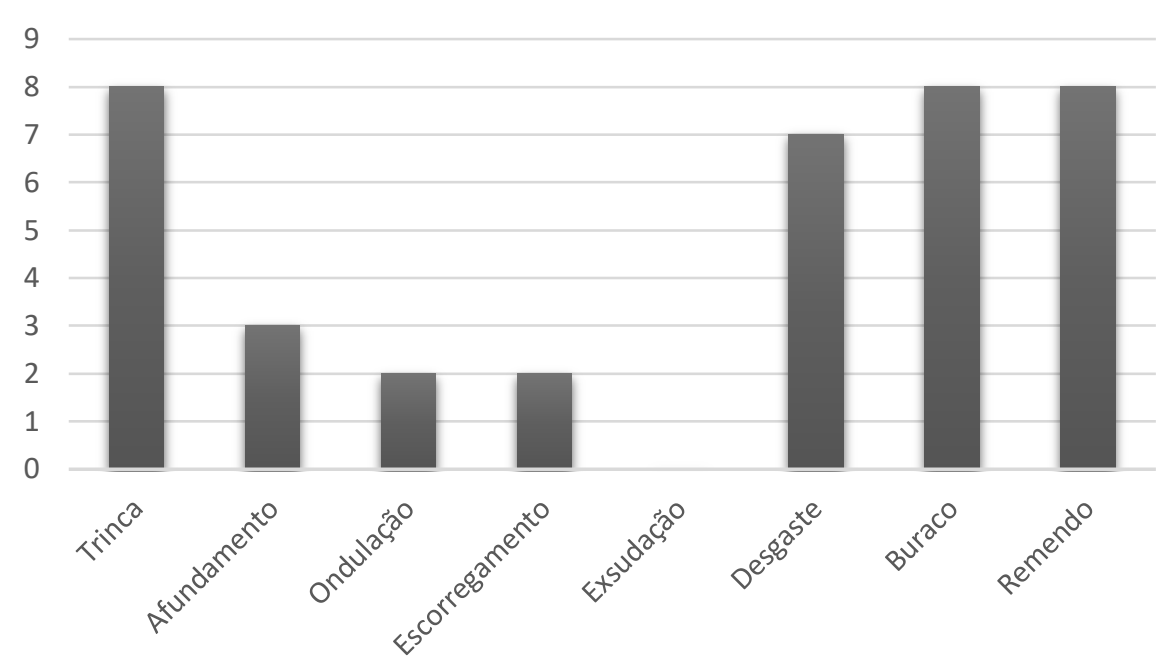

Após catalogados e compilados os dados, o levantamento de campo permitiu constatar o elevado grau de degradação e o mau estado de conservação das vias da cidade, configurada em um alto índice de anomalias. Embora a deterioração dos pavimentos asfálticos urbanos seja um processo natural que ocorrerá ao longo dos anos devido ao uso e ações de intempéries, pode ser amenizado através de procedimentos de intervenção capazes de aumentar a vida útil dos mesmos e garantir seu bom desempenho. Após o surgimento dos defeitos, tão logo seja possível, devem ser aplicadas técnicas de recuperação, de forma a evitar que os mesmos se agravem ou que levem ao surgimento de novos defeitos.

Diante do escopo do trabalho de se propor medidas de correção, realizou-se verificação in situ dos problemas de superfície, com o objetivo de levantar as possíveis causas que levaram ao seu aparecimento. Oliveira et. al. (2019) mencionam como possíveis causas para as manifestações patológicas:

i) Trincas são resultados da fadiga, da retração térmica, dos processos de consolidação, das juntas de construção e idade, podendo esses fatores ocorrerem em conjunto (um ou mais) ou separadamente, dependo da intensidade da anomalia;

ii) Panelas ou buracos surgem devido à falta de aderência entre as camadas do pavimento, que causa o desplacamento ou devido ao acúmulo de água no pavimento podendo também serem resultantes da evolução de trincas, afundamentos e desgaste;

iii) Desgastes são decorrentes dos esforços tangenciais do tráfego associados ao intemperismo e ocorrem em idade avançada do pavimento;

iv) Escorregamentos são defeitos decorrentes da má compactação das camadas superiores e/ou do aumento de temperatura da superfície do pavimento e/ou do alto fluxo do tráfego.

Outro fator relacionado ao aparecimento dessas anomalias, para este estudo de caso, é a falta de serviços de manutenção e gestão das vias urbanas. Vale destacar que, segundo dados fornecidos pela Prefeitura de Juiz de Fora (PJF, 2021), somente no mês de fevereiro do corrente ano foram empenhados o valor de $\mathrm{R} \$ 14.384 .288$ para obras de pavimentação asfáltica a serem realizadas pela Empresa Municipal de Pavimentação e Urbanização (EMPAV), correspondendo a 1,56\% do total de despesas empenhadas pelo município. Desse valor empenhado, somente R $\$ 1.173 .492,82$ foram de fato liquidados, o que corresponde a $0,56 \%$ do total de despesas liquidadas pelo município, constatando o irrisório investimento providenciado pelo órgão municipal responsável. 
Com isto, a ocorrência dos defeitos na pavimentação asfáltica da cidade vincula-se ao comprometimento do setor público aos investimentos em medidas de execução, manutenção ou correção dos pavimentos, bem como a erros de: projetos, técnicas, especificação de materiais, dados de tráfego que não condizem com a realidade atual, entre outros. Portanto, para a execução das medidas de reparos, deve-se realizar o diagnóstico do asfalto de forma a optar pelo procedimento mais adequado e efetuá-lo da maneira correta, uma vez que uma técnica de reparo mal executada pode postergar o aparecimento de danos futuros ou somente agir paliativamente em um defeito, sem de fato corrigir sua causa.

Diante do exposto, faz-se necessária a reparação no pavimento urbano de Juiz de Fora de forma a melhorar a mobilidade urbana. Anteriormente, vale contextualizar a diferença entre restauração e reconstrução: a restauração é o conjunto de operações destinadas a restabelecer na íntegra ou em parte as características originais de um pavimento e inclui as ações de manutenção preventiva e reforço; enquanto a reconstrução é a operação de refazer o pavimento no todo, desde o subleito, por retirada total dos materiais da base e revestimentos antigos e substituição por novos materiais ou por reciclagem dos mesmos (BERNUCCI et. al., 2006).

A partir disto, para que se torne possível estabelecer técnicas de restauração é necessário realizar o estudo da condição do pavimento, onde verifica-se a condição da superfície do pavimento como áreas trincadas e sua severidade, deformações permanentes e irregularidades longitudinais e as condições da estrutura do pavimento (BERNUCCI et. al., 2006). Ressalva-se que neste estudo não foi realizada uma avaliação estrutural dos pavimentos.

A norma do DNER 159/85, referente a Projeto de Recuperação de Pavimentos Flexíveis, estabelece os seguintes critérios para a escolha do tipo de restauração apropriada: "a) para a correção da irregularidade: restauração em concreto asfáltico; b) para a correção do trincamento ou do desgaste: restauração em lama asfáltica ou tratamento superficial ou em concreto asfáltico".

BERNUCCI, et. al. 2006 apresentam como métodos de restauração: a lama asfáltica que consiste em uma mistura fluida de agregados minerais, material de enchimento ou fíler, emulsão asfáltica e água, despejados no local da obra à temperatura ambiente, sendo geralmente empregada na manutenção de pavimentos que apresentam desgaste superficial ou pequeno grau de trincamento, agindo como um impermeabilizante, sendo uma alternativa viável para selagem de trincas e rejuvenescimento do asfalto; o concreto asfáltico, que consiste numa mistura à frio, processada em usina móvel especial, de agregados minerais, fíler, água e emulsão com adição de polímero; eventualmente pode conter também adição de fibras e o tratamento superficial realizado pela aplicação de ligantes asfálticos e agregados na pista, isto é, os materiais são dispostos sem mistura prévia no local, primeiro colocam-se os ligantes, depois os agregados, logo após os materiais sofrem compactação, responsável por promover a adesão e o recobrimento parcial da superfície. Dessa forma, o tratamento superficial aumenta a resistência ao desgaste, impermeabiliza e protege a infraestrutura dos pavimentos.

Ainda sobre as correções de defeitos funcionais superficiais, Bernucci et. al. (2006) destaca as seguintes normas e procedimentos, que podem ser isolados ou combinados, e antecedidos ou não de uma remoção de parte do revestimento antigo:

- Para a selagem de trincas, rejuvenescimento e restauração da aderência de superfícies podem ser utilizadas as técnicas de lama asfáltica (DNER-ES 314/97), tratamento superficial simples ou duplo (DNER-ES 308/97 e DNER-ES 309/87), microrrevestimento asfáltico a frio ou a quente (ABNT NBR 14948, DNIT 035/2005-ES, DNER-ES 388/99), entre outras.

- Para a correção de defeito funcional de irregularidade elevada, pode-se utilizar o concreto asfáltico (DNIT 031/2004).

- Para melhorar as condições de atrito e o escoamento da água superficial, pode-se utilizar mistura do tipo camada porosa de atrito, Stone Matrix Asphalt (SMA) ou misturas descontínuas (DNER-ES 386/99). 
Além destas soluções, para o tratamento de trincas pode-se realizar alteração das propriedades da mistura asfáltica, alteração da estrutura do pavimento com incorporação de sistemas de rachaduras antirreflexo colocados na zona intermediária, com o uso de geotêxteis, geogrelhas, redes de aço, entre outros (OLIVEIRA et. al., 2019).

Outro método de reparo utilizado nas panelas (sejam elas causadas pelo desgaste do tráfego ou por interferências de reparos nas redes de água, esgoto e etc) é o remendo. Para a execução do remendo retira-se toda a sujeira ou água presente no defeito, executa-se um corte retangular na área com 20 ou $30 \mathrm{~cm}$ além das extremidades e profundidade suficiente para encontrar um material consistente, em seguida realiza-se a imprimação, é lançado o asfalto e por fim, a compactação. No caso de buraco muito profundo deve-se realizar a recuperação das camadas de sustentação do pavimento (ROCHA, 2010; RIBEIRO, 2017; OLIVEIRA et. al., 2019).

Já para a correção de desgaste pode-se utilizar o método da lama asfáltica ou microrrevestimento citados acima, ou ainda outro método utilizado para reduzir os custos, que consiste na aplicação de uma camada de cimento Portland diretamente sobre a superfície existente com espessuras entre 100 e 280 mm (MAGALHÃES, 2014; ISLA et. al., 2015; RIBEIRO, 2017).

Além dessas técnicas apresentadas, para a correção dos afundamentos e das corrugações ou ondulações, recomenda-se a aplicação de recapeamento e fresagem. O recapeamento consiste na construção de uma ou mais camadas asfálticas sobre o pavimento existente, enquanto a fresagem é o procedimento de remoção do revestimento antigo e sugere-se realizá-la previamente ao recapeamento de forma a evitar a propagação dos defeitos (ROCHA, 2010).

As técnicas expostas acimas podem ser utilizadas para a correção das manifestações patológicas encontradas nas vias do município de Juiz de Fora de forma a melhorar o conforto e segurança dos usuários e aumentar a vida útil dos pavimentos. Como o trabalho limitou-se a uma análise funcional e não estrutural dos pavimentos, não foi possível apontar a técnica mais adequada para cada caso específico, dessa forma, espera-se que o mesmo possa contribuir para futuras pesquisas que se aprofundem no diagnóstico das anomalias.

\section{CONCLUSÕES}

As manifestações patológicas nos pavimentos asfálticos urbanos podem aparecer devido a diversos fatores tais como níveis de tráfego, clima, entre outros. O surgimento das patologias pode ocasionar diversos prejuízos aos motoristas e pedestres das cidades, aumentando o número de acidentes de trânsito, danos mecânicos aos veículos e aumento do tempo das viagens. Portanto, para o usuário, o estado da superfície do pavimento é um ponto importante, uma vez que defeitos e irregularidades na pista afetam seu conforto e segurança.

De forma a garantir a qualidade da mobilidade urbana, o trabalho se propôs a identificar e mapear as manifestações patológicas presentes nas vias urbanas de Juiz de Fora; verificar a ocorrência e apontar as manifestações patológicas de maior incidência nas vias de estudo; e propor soluções de reparação contidas na bibliografia existente. Todos os objetivos foram alcançados.

Através do levantamento visual realizado e do registro de fotografias constatou-se a presença de inúmeras anomalias nas ruas do município que se encontram em péssimo estado de conservação, gerando transtornos à população. Aproximadamente $60 \%$ do pavimento de toda a região de estudo encontra-se comprometida com a presença de um ou mais defeitos e as manifestações patológicas de maior ocorrência foram as trincas, buracos e remendos, presentes em todas as regiões. $\mathrm{O}$ trabalho também alcançou seu objetivo ao apresentar de maneira sucinta e objetiva técnicas de recuperação que podem ser utilizadas na correção desses defeitos, de acordo com a bibliografia existente. 
Espera-se que o artigo alerte a sociedade para a importância de exigir da gestão municipal condições adequadas que garantam o conforto e a segurança dos usuários no usufruto do direito básico de ir e vir.

\section{AGRADECIMENTOS}

Agradecimentos ao CNPq- Conselho Nacional de Desenvolvimento Científico e Tecnológico e à CAPES- Coordenação de Aperfeiçoamento de Pessoal de Nível Superior.

\section{REFERÊNCIAS} Janeiro, 1985.

DNER-PRO 159/85: Projeto de Restauração de Pavimentos Asfálticos. Rio de

ACESSA.COM. Disponível em: $<$ https://www.acessa.com/jfmapas/regioes.php $>$. Acesso em: 26/01/2021.

ALMEIDA, Camila da Silva (2019), "Patologias em vias urbanas: Estudo de caso na cidade de Maceió-Alagoas”. Trabalho de Conclusão de Curso. Centro Universitário Cesmac. Maceió, p.37.

Associação Brasileira de Normas Técnicas. (1982). NBR 7207: Terminologia e Classificação de Pavimentação. Rio de Janeiro.

BERNUCCI, L. B. et. al. (2006), "Pavimentação Asfáltica: Formação básica para engenheiros". Livro. Rio de Janeiro: PETROBRAS: ABEDA. p. 504.

BRASIL (1997), “Código de Trânsito Brasileiro”, Lei N 9.503, de 23 de setembro de 1997.

Disponível em: <http://www.planalto.gov.br/ccivil 03/leis/19503.htm. $>$. Acesso em: 01/02/2021.

CAETANO, Fernando Domingues (2013), "Classificação de vias urbanas: o Código de Trânsito Brasileiro e os planos diretores municipais no estado do Paraná”, Monografia de especialização, Universidade Tecnológica Federal do Paraná, Curitiba, p. 65.

CALLEJAS, Ivan Júlio Apolônio; DURANTE, Luciane Cleonice; ROSSETI, Karyna de Andrade Carvalho (2015), Pavimentação Asfáltica: Contribuição no Aquecimento de Áreas Urbanas. $E \& S$ Engineering and Science, v. 3, n. 1, p. 64-72, 2015. Disponível em:

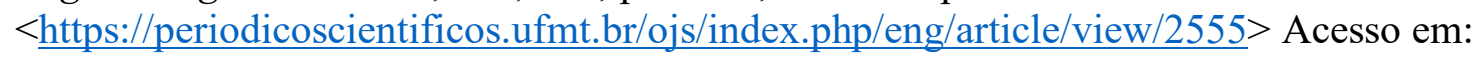
27/01/2021.

DANIELESKI, Maria Luiza (2004), "Proposta de metodologia para avaliação superficial de pavimentos urbanos: aplicação à rede viária de Porto Alegre”, Dissertação, Universidade Federal do Rio Grande do Sul, Porto Alegre, p. 187.

DENATRAN. Departamento Nacional de Trânsito. Frota de veículos. 2019. Disponível em:

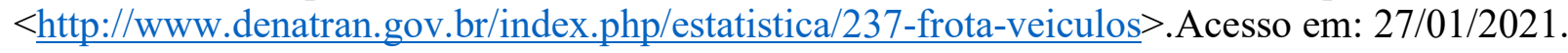

DNIT (2003), “Defeitos nos pavimentos flexíveis e semi-rígidos Terminologia." Norma. Ministério dos Transportes - Departamento Nacional de Infraestrutura de Transportes - Instituto de Pesquisas Rodoviárias. Rio de Janeiro. 
DNIT (2006), "Manual de estudos de tráfego”, Ministério dos Transportes - Departamento Nacional de Infraestrutura de Transportes - Instituto de Pesquisas Rodoviárias, Rio de Janeiro.

FRANÇA, Frederico Lemos \& FERNANDES, Társis Maday Jorge (2017), "Patologias em Pavimento Asfáltico", Trabalho de Conclusão de Curso, Curso de Engenharia Civil, UniEvangélica, Anápolis, GO, p. 57.

IBGE - INSTITUTO BRASILEIRO DE GEOGRAFIA E ESTATÍSTICA (2011), Sinopse do Censo Brasileiro de 2010. Rio de Janeiro. p. 261.

MELO, Bruna Pinheiro de (2004), “Indicadores de ocupação urbana sob o ponto de vista da infraestrutura viária”, Dissertação (Mestrado em Engenharia de Transportes) - Instituto Militar de Engenharia, Rio de Janeiro, p. 184.

MENDES, Alesi Teixeira (2019), "Levantamento Visual de Patologias em Pavimentos Flexíveis de Vias Urbanas em Araguaína-TO”. Artigo. Congresso Técnico Científico da Engenharia e da Agronomia CONTECC. Palmas/TO. Disponível em:

$<$ https://www.confea.org.br/sites/default/files/uploadsimce/Contecc2019/Civil/LEVANTAMENTO\%20VISUAL\%20DE\%20PATOLOGIAS\%20EM \%20PAVIMENTOS $\% 20$ FLEX $\%$ C3\%8DVEIS $\% 20$ DE $\% 20$ VIAS $\% 20$ URBANAS $\% 20$ EM $\% 20$ A RAGUAINA\%20-\%20TO.pdf> Acesso em 27/01/2021.

OLIVEIRA, D. C. et. al. (2019), Identificação de Manifestações Patológicas em Pavimentos Asfálticos na Cidade de Santa Margarida-Mg. Pensar Acadêmico, v. 17, n. 1, p. 33-42.

Disponível em:

<http://www.pensaracademico.facig.edu.br/index.php/pensaracademico/article/view/703> Acesso em: 23/03/2021.

PJF - PREFEITURA DE JUIZ DE FORA. Despesas públicas. Portal da Transparência. Juiz de Fora. 2021. Disponível em:

$<\underline{\text { https://www.pjf.mg.gov.br/transparencia/despesas_publicas/mensal_consolidada/index.php }>}$ Acesso em: 23/03/2021.

QUIRINO, Marina Eliza Pacifico (2013), "Recuperação de pavimentos flexíveis em áreas de taxiamento de aeronaves: um estudo de caso da pista fox-2 do Aeroporto Internacional Tancredo Neves-MG”, Monografia, Escola de Engenharia da Universidade Federal de Minas Gerais, Belo Horizonte. p. 79.

ROCHA, Robson Soares (2010), "Patologias de pavimentos asfálticos e suas recuperaçõesestudo de caso da Avenida Pinto de Aguiar", Universidade Católica de Salvador. p. 24.

SAVIETTO, Júlia Panzarin (2017), "Análise de impactos ambientais da restauração de um pavimento asfáltico pela Avaliação do Ciclo de Vida", Tese de Doutorado, Universidade de São Paulo. p. 110. 